\title{
Динамика физической подготовленности первокурсниц курганского государственного университета
}

\author{
Ловъгина О.Н.1 , Корюкин Д.А. ${ }^{1}$, Сидоров Р.В. ${ }^{*}$ * \\ ${ }^{1}$ Курганский государственный университет \\ 2. Курган, Россия \\ ORCID: oooo-ooo1-5455-7240, kapitan77770n@mail.ru \\ ORCID: oooo-ooo1-7815-5676, krjukin.dimn@mail.ru \\ 2 Уральский государственный экономический университет \\ г. Екатеринбург, Россия \\ ORCID: ooooo-00o2-0295-935X, sidorov_rv@usue.ru*
}

\begin{abstract}
Аннотация: Физическая культура является частью общей культуры человека, направленной на гармоничное развитие личности с помощью специально организованной двигательной активности. Она также является одним из средств укрепления здоровья, оптимизации физического, функционального и психологического состояния человека. Материалы. Динамика физической подготовленности девушек, поступивших на первый курс Курганского государственного университета. Методы исследования. Анализ и обобщение научной литературы, педагогическое наблюдение,метод контрольных испытаний и методы математической статистики. Резулътатъ. В статье представлены результаты многолетнего наблюдения за общей физической подготовленностью девушек - первокурсниц Курганского государственного университета. Показано, что самая низкая физическая подготовленность отмечалась в 2010-2012 годах. В последующие годы происходилопостепенное, волнообразноеснезначительным снижением повышениеобщей физической подготовленности девушек. Заключение. Если рассматривать полученные в ходе многолетнего наблюдения данные с позиций физического здоровья, то можно сказать, что начиная с 2012-2013 учебного года отмечается улучшение функционального состояния основных систем организма девушек 17-18 лет, обучающихся в Курганском государственном университете. Такая постепенная положительная динамика общей физической подготовленности девушек, возможно, обусловлена активным вниманием государства к физической культуре и спорту.

Ключевые слова: физическая культура, физическая подготовленность, улучшение здоровья.
\end{abstract}

Для цитирования: Ловыгина О.Н., Корюкин Д.А., Сидоров Р.В.* Динамика физической подготовленности первокурсниц курганского государственного университета. Педагогикопсихологические и медико-биологические проблемы физической культуры и спорта. 2020; 15(4): 61-66. DOI: 10.14526/2070-4798-2020-15-4-61-66

\section{Dynamics of physical readiness in female first-year-students of Kurgan State University}

\author{
Oksana N. Lovygina1, Dmitrij A. Koryukin1, Roman V. Sidorov2* \\ ${ }^{1}$ Kurgan State University \\ Kurgan, Russia \\ ORCID: oooo-ooo1-5455-7240, kapitan77770n@mail.ru \\ ORCID: oooo-ooo1-7815-5676, krjukin.dimn@mail.ru \\ 2Ural State Economic University \\ Ekaterinburg, Russia \\ ORCID: ooooo-ooo2-0295-935X, sidorov_rv@usue.ru*
}

\begin{abstract}
Physical culture is a part of a person's general culture, directed toward harmonious personality development with the help of specially organized motor activity. It is also one of the means of a person's health improvement, physical, functional and psychological state optimization. Materials. Dynamics of physical readiness in female students of the first course of Kurgan State
\end{abstract}


University. Research methods. Information sources analysis and summarizing, pedagogical observation, method of control tests and methods of mathematical statistics. Results. The article presents the results of a long-term observation over general physical readiness of female firstyear students from Kurgan State University. It is shown that the lowest physical readiness was in 2010-2011. During further years there was gradual, wavy increase of general physical readiness in girls. Conclusion. If we consider received during the observation results from the position of physical health, we can say that since 2012-2013 there was functional state improvement of the main organism systems in 17-18 year-old girls, who studied at Kurgan State University. Such kind of gradual positive dynamics of general physical readiness in girls, might be conditioned by attention of the state to physical culture and sport.

Keywords: physical culture, physical readiness, health improvement.

For citation: Oksana N. Lovygina, Dmitrij A. Koryukin, Roman V. Sidorov*. Dynamics of physical readiness among female first-year-students of Kurgan State University. Russian Journal of Physical Education and Sport. 2020; 15(4): 61-66. DOI: 10.14526/2070-4798-2020-15-4-61-66

\section{ВВЕДЕНИЕ}

Физическая культура является частью общей культуры человека, направленной на гармоничное развитие личности с помощью специально организованной двигательной активности. Она также является одним из средств укрепления здоровья, оптимизации физического, функционального и психологического состояния человека. В исследовании О.А. Сбитневой показано, что современные девушки осознают значимость физической культуры и спортадля поддержания здорового образа жизни, укрепления здоровья и улучшения внешнего вида $[1,2,3,4,5,6]$.

Целью данной работыявлялось изучение динамики физической подготовленности девушек, поступивших на первый курс Курганского государственного университета.

Исходя из цели, объектом исследования являлся процесс физического воспитания студенток, предметом исследования физическая подготовленность первокурсниц.

В исследовании приняли участие 628 студенток в возрасте 17-18 лет, обучающихся на первых курсах в Курганском государственном университете с 2010 по 2019 годы.Все девушки по заключению врача были отнесены к основной медицинской группе и на момент тестирования жалоб по здоровью не предъявляли.

\section{МАТЕРИАЛЫ И МЕТОДЫ}

Для достижения поставленной цели были использованы следующие методы: статистический метод. Для определения физической подготовленности первокурсниц Курганского государственного университета был использован метод контрольных испытаний, включающий следующие тесты: прыжок в длину с места (см), поднимание и опускание туловища из положения лежа на спине (кол-во раз), в упоре сгибание и разгибание рук (кол-во раз), бег 100 метров (сек).

\section{РЕЗУЛЬТАТЫ И ОБСУЖДЕНИЕ}

В тесте «прыжок в длину с места» у студенток наименьший результат за период наблюдения был зафиксирован в 2010-2011

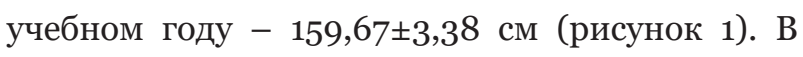
последующие 5 лет отмечался постепенный рост результатов в данном тесте. В 2016-2017 учебном году у первокурсниц было зафиксировано снижение результата на 5,12 см. За девять лет наблюдений средний результат в тесте «прыжок в длину с места» у девушек вырос на 7,62 см, что составляет $5 \%$.

В тесте «поднимание и опускание туловища из положения лежа на спине» колебания средних результатов с 2012 по 2019 годы были незначительными (рисунок 2). Большевсего подниманий и опусканий туловища

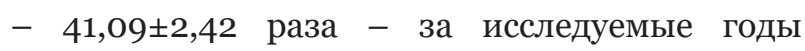
девушки смогли сделать в 2018-2019 учебном году. Наименьшее количество повторений сгибания туловища первокурсницы выполнили

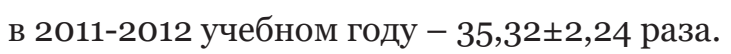




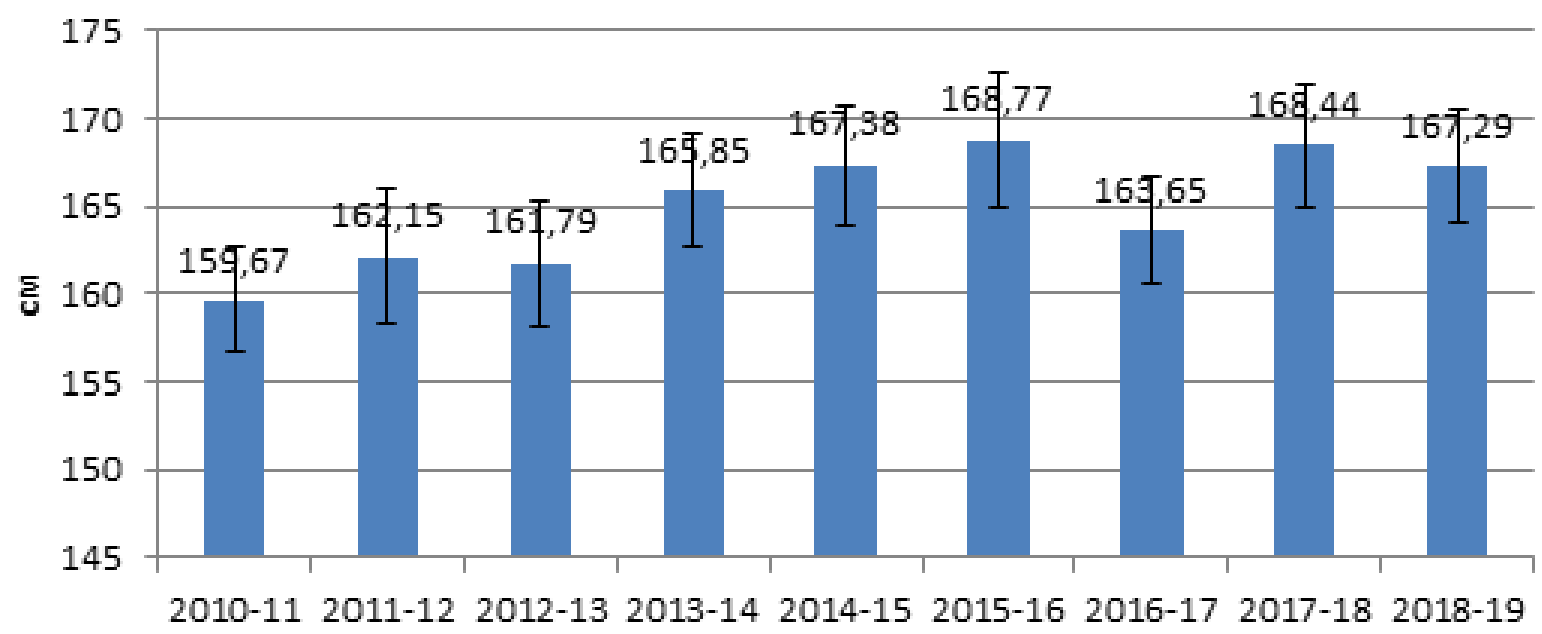

Рисунок 1. Средние результаты в тесте «прыжок в длину с места»

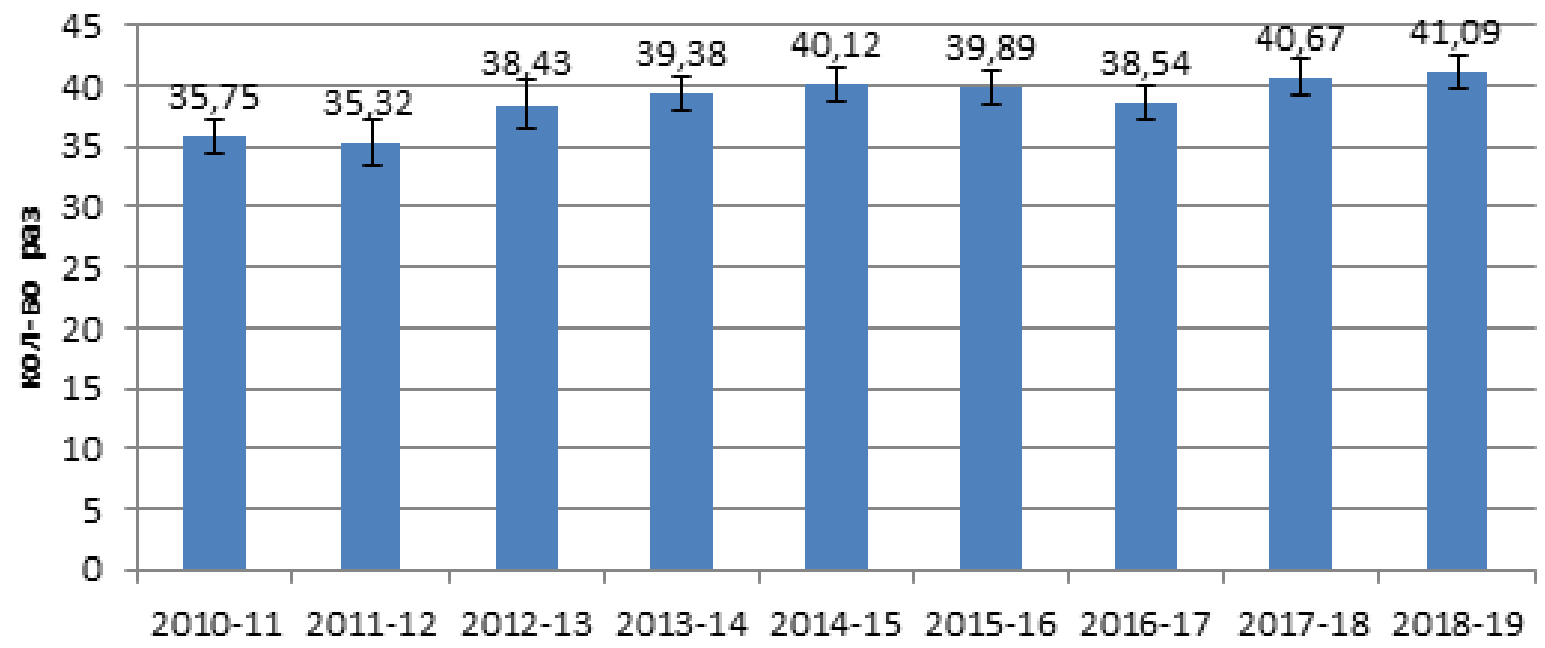

Рисунок 2. Средние результаты в тесте «поднимание и опускание туловища из положения лежа на спине»

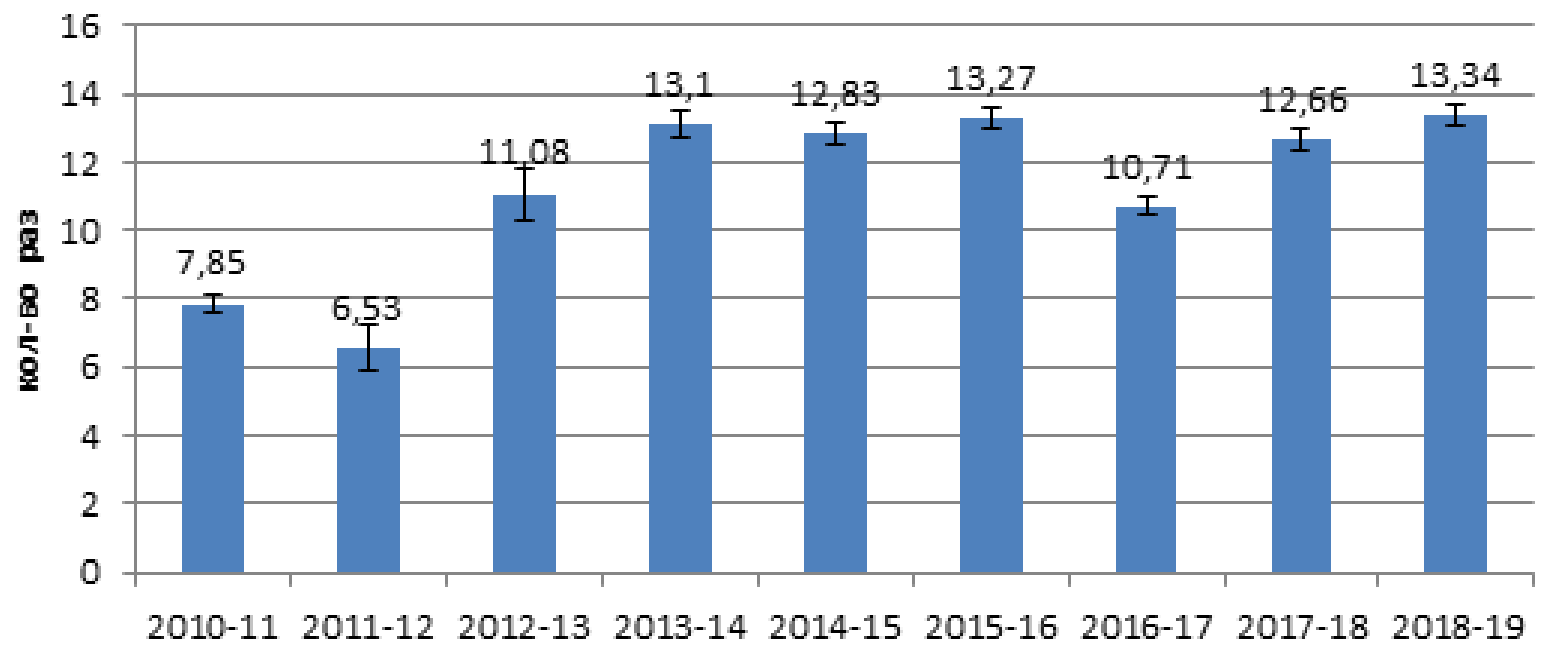

Рисунок 3. Средние результаты в тесте «в упоре сгибание и разгибание рук» 
В тесте «в упоре сгибание и разгибание рук» в 2011-2012 учебном году первокурсницы показали самый низкий средний результат 6,53 $\pm 3,03$ раза (рис. 3). Максимальный средний результат девушками был установлен в 2018-

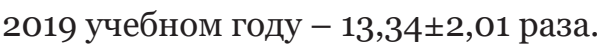

В тесте напроявление скоростных качеств человека «бег 100 метров» девушкипоказали

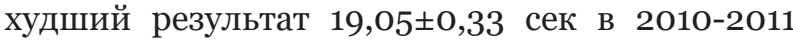
учебном году. Быстрее всего эту дистанцию они преодолевали в 2018-2019 учебном году, в

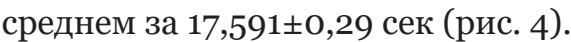

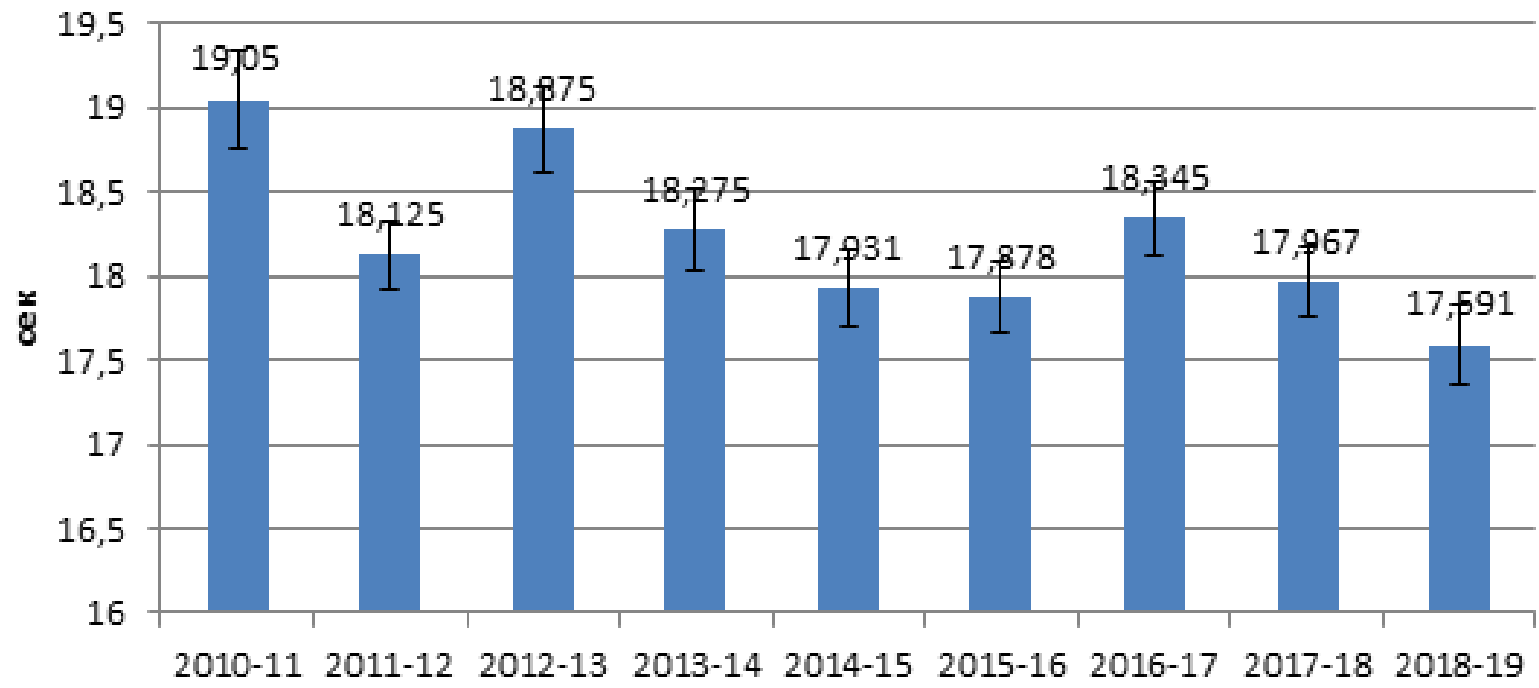

Рисунок 4. Средние результаты в тесте «бег 100 метров»

Анализ средних результатов по всем тестам показывает, что за девять лет наблюдений больше всего изменились результаты в тесте «в упоре сгибание и разгибание рук» (на 70\%).
В тесте «прыжок в длину с места» результаты за период исследования с 2010 по 2019 год улучшились лишь на $5 \%$ (рисунок 5).

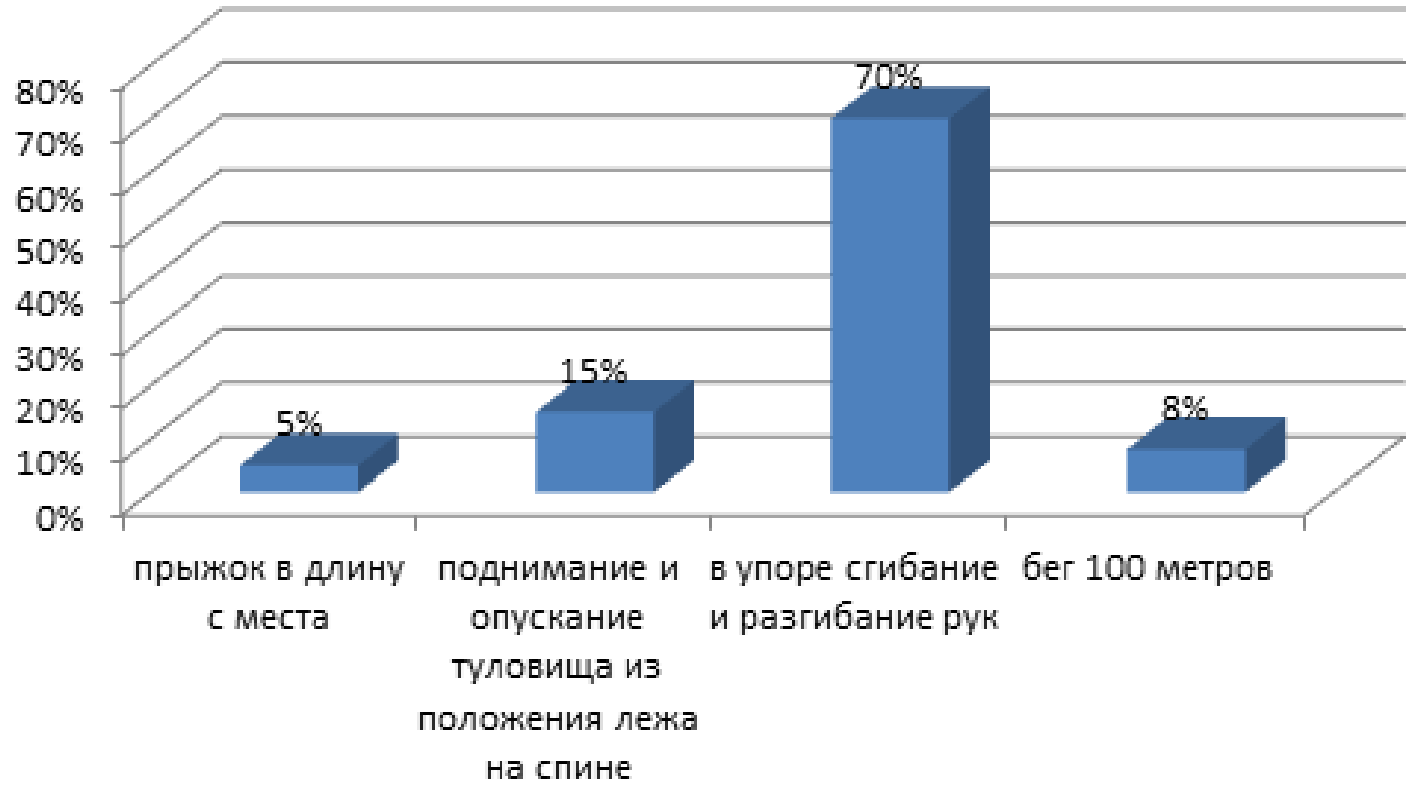

Рисунок 5. Процент изменения результатов в тестах за период исследования 
За период наблюдения отмечено, что худшие результаты в трех предложенных тестах были у девушек, поступивших на первый курс в 2010-2011 учебном году. В тесте «в упоре сгибание и разгибание рук» самый низкий результат был зафиксирован в 2011-2012 учебном году. Также хочется отметить, что в 2016-2017 учебном году первокурсницы оказались менее физически подготовленными, чем в предыдущий и последующие годы.

Как известно, физическая
подготовленность человека отражает уровень развития его физических качеств (силы, быстроты, выносливости, гибкости, ловкости), а также степень владения двигательными умениями и навыками, необходимыми для успешного осуществления определенного рода деятельности. Внешние проявления физической подготовленности человека обеспечиваются функциональными возможностями систем организма, деятельностью костно-мышечной, дыхательной, сердечно-сосудистой, нервной и других систем организма.

Тест «прыжок в длину с места» предназначен для оценки скоростносиловых способностей, которые отражают функциональную работоспособность мышц ног и спины, в частности сгибателей стопы, четырехглавой, ягодичной и длинной мышцы спины, а также эффективность нервномышечной регуляции, которая, в свою очередь, обусловливается способностью нервной системы к проведению нервных импульсов, синхронизации сокращения и расслабления двигательных единиц.

Тест«в упоре сгибание и разгибание рук» используется для оценки силы и силовой выносливости мышц верхнего плечевого пояса: широчайшей мышцы спины, а также сгибателей рук и грудных мышц.

Тест «поднимание и опускание туловища из положения лежа на спине» также используется для оценки силы и силовой выносливости мышц туловища, так как в нем задействованы прямые мышцы живота и бедра, напрягатели фасций и косые мышцы области живота.

Бег на 100 метров является интегральным показателем, отражающим быстроту человека, это циклическое упражнение максимальной мощности. Успешность выполнения этого упражнения зависит от анаэробных механизмов энергообеспечения организма, а также от максимальной изометрической, скоростной динамической и «взрывной» силы мышц ног.

Если рассматривать полученные в ходе многолетнего наблюдения данные с позиций физического здоровья, то можно сказать, что начиная с 2012-2013 учебного года отмечается улучшение функционального состояния основных систем организма девушек17-18 лет, обучающихся в Курганском государственном университете. Такая постепенная положительная динамика общей физической подготовленности девушек, возможно, обусловлена активным вниманием государства к физической культуре и спорту.

\section{ЗАКЛЮЧЕНИЕ}

1. Определение физической подготовленности студенток-первокурсниц Курганского государственного университета выявило, что за весь период наблюдения максимальные результаты в предложенных тестах были показаны в 2018-2019 учебном году.

2. Минимальный средний результат среди девушек за девять лет наблюдения был отмечен в 2010-2011 учебном году в тестах «прыжок в длину с места»и«бег 100 метров». В тестах «поднимание и опускание туловища из положения лежа на спине» и «в упоре сгибание и разгибание рук» худший результат был зафиксирован в 2011-2012 учебном году.

3. Анализ динамики физической подготовленности д девушек-первокурсниц Курганского государственного университета выявил, что по всем тестамначиная с 20122013 учебного года отмечается постепенное улучшение среднего результата от года к году, но с незначительным снижением в 2016-2017 учебном году.

\section{СПИСОК ЛИТЕРАТУРЫ}

1. Сбитнева О.А. Место физической культуры и спорта в жизни современных 


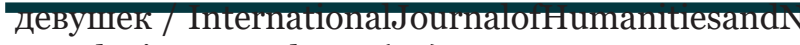

aturalSciences, vol. 4-3 (43), 2020, p. 46-50.

2. Кривошапкин П.И. Анатомия с основами спортивной морфологии: учебное пособие. Якутск: Издательский дом СВФУ. 2019. URL: https://coollib.net/b.usr/P. I. Krivoshapkin Anatomiya $s$ osnovami sportivnoy morfologii.PDF.

3. Кузнецов А.С., Кузнецова 3.М. ІІ Съезд членов общественной организации «Российское профессорское собрание». П Педагогикопсихологические и медико-биологические проблемы физической культуры и спорта. 2019; 14(4): 5-7. DOI: 10.14526/2070-4798-201914-4-5-7.

4. Emerenziani G.P., Guidetti L., Gallotta
M.C., Franciost E., Buzzacnera C.F., Baraarr C. Exercise intensity and gender difference of 3 different salsa dancing conditions. International Journal of Sports Medicine. 2013; 34: 330-345.

5. Filipa A., Byrnes R., Paterno M.V., Myer G.D., Hewett T.E. Neuromuscular training improves performance on the star excursion balance test in young female athletes. Journal of Orthopaedic and Sports Physical Therapy. 2010; 40: 551-558. DOI: 10.2519/jospt.2010.3325.

6. Keating X.D., Guan J., Pinero J.C., Bridges D.M. A meta-analysis of college students' physical activity behaviors. Journal of American College Health. 2005; 54: 116-126. DOI: 10.3200/ JACH.54.2.116-126.

\section{Статья поступила в редакцию: 14.11.2020}

Ловыгина Оксана Николаевна - кандидат биологических наук, доцент, Курганский государственныйуниверситет, 640о20, Россия, г.Курган, ул.Советская, 63, e-mail:kapitan777оп@ mail.ru

Корюкин Дмитрий Анатольевич - кандидат биологических наук, доцент, Курганский государственный университет, 640020, г. Курган, ул. Советская, 63, e-mail: krjukin.dimn@mail. $\underline{r u}$

Сидоров Роман васильевич - кандидат биологических наук, доцент, Уральский государственный экономический университет, 620144, Россия, г. Екатеринбург, ул. 8 Марта/ Народной Воли, 62/45, e-mail: sidorov rv@usue.ru 